International Journal of Automotive and Mechanical Engineering (IJAME)

ISSN: 2229-8649 (Print); ISSN: 2180-1606 (Online); Volume 8, pp. 1267-1277, July-December 2013

(C) Universiti Malaysia Pahang

DOI: http://dx.doi.org/10.15282/ijame.8.2013.16.0104

\title{
EVALUATION OF ANNOYANCE AND SUITABILITY OF A BACK-UP WARNING SOUND FOR ELECTRIC VEHICLES
}

\author{
I. Salleh ${ }^{1, *}$, M.Z. Md. Zain ${ }^{1}$ and R.I. Raja Hamzah ${ }^{1}$ \\ ${ }^{1}$ Department of Applied Mechanics and Design, \\ Faculty of Mechanical Engineering, Universiti Teknologi Malaysia, \\ 81310 UTM Skudai, Johor, Malaysia \\ *Email: ismasyariff@ gmail.com \\ Phone: +60-7-5534617; Fax: +60-7-5576820
}

\begin{abstract}
This paper describes the evaluation of the annoyance and suitability of a back-up warning sound for electric vehicles (EV). Three back-up signals used for the evaluation were categorized into three types: broadband, tonal and multi-tone. The reversing sound for a Nissan Leaf (EV-first mass production) will also be included as a benchmark for the other three sound signals. The sample sound was generated based on the human hearing threshold in several individual related areas; age-related, normal and working noise exposure frequency range. Each sound was evaluated in turn by the respondents in a nearby neighborhood, college, town area and rural area in terms of level of annoyance and its suitability as an EV back-up sound to alert pedestrians as they run quietly on the road, which can cause a hazard. Every tested sound perception result is based on the place where the respondents live. An appropriate sound for a quiet vehicle can help pedestrians to detect it and at the same time maintain acceptable environmental sound levels.
\end{abstract}

Keywords: Electric vehicle warning sound; back-up s $\quad$ d; annoyance and suitability.

\section{INTRODUCTIOI}

Since EVs run on an electric motor, less noise is produced and emitted to the environment compared to vehicles with internal combustion engines (ICE). The critical condition occurs especially when EVs are traveling at low speed or backing up, when they become very quiet, although at speeds higher than $30-40 \mathrm{~km} / \mathrm{h}$, the tire and wind friction of the EV can produce enough noise to alert people in the vicinity (Zeitler, 2012). Therefore, pedestrians (especially visually impaired people and cyclists) have difficulty recognizing a vehicle that is approaching them at a low speed or backing up (Tabata et al., 2011). For pedestrians, who have counted for generations on hearing the typical rumble of an ICE approaching, without turning to look, their ability to hear and judge the direction of approaching vehicles has been critical in avoiding collisions. For a visually impaired person, audible information coming from the vehicle is the only source of information that they can use to detect its presence and location. The objective of the research is to evaluate three tones on their annoyance and suitability for quiet EVs according to several respondents in different areas.

In a Japanese measurement report (JASIC, 2009), they tested noise levels emitted by EVs at low speed conditions that possess inaudible noise compared with two ICE vehicles at 0 to $35 \mathrm{~km} / \mathrm{h}$, as shown in Figure 1 . From the figure, when the vehicle was in the idle condition, the difference in noise level between the EV and the two ICE 
vehicles was $20 \mathrm{~dB}$. When the vehicle started to move, the differences in noise level decreased and at $15 \mathrm{~km} / \mathrm{h}$ only about $3-4 \mathrm{~dB}$ separated the EV and ICE vehicles. When the EV started to speed up to $30-40 \mathrm{~km} / \mathrm{h}$, tire and wind friction produced noise that made the car more obvious to road users and the noise level started to level up with the ICE vehicles (Zeitler, 2012).

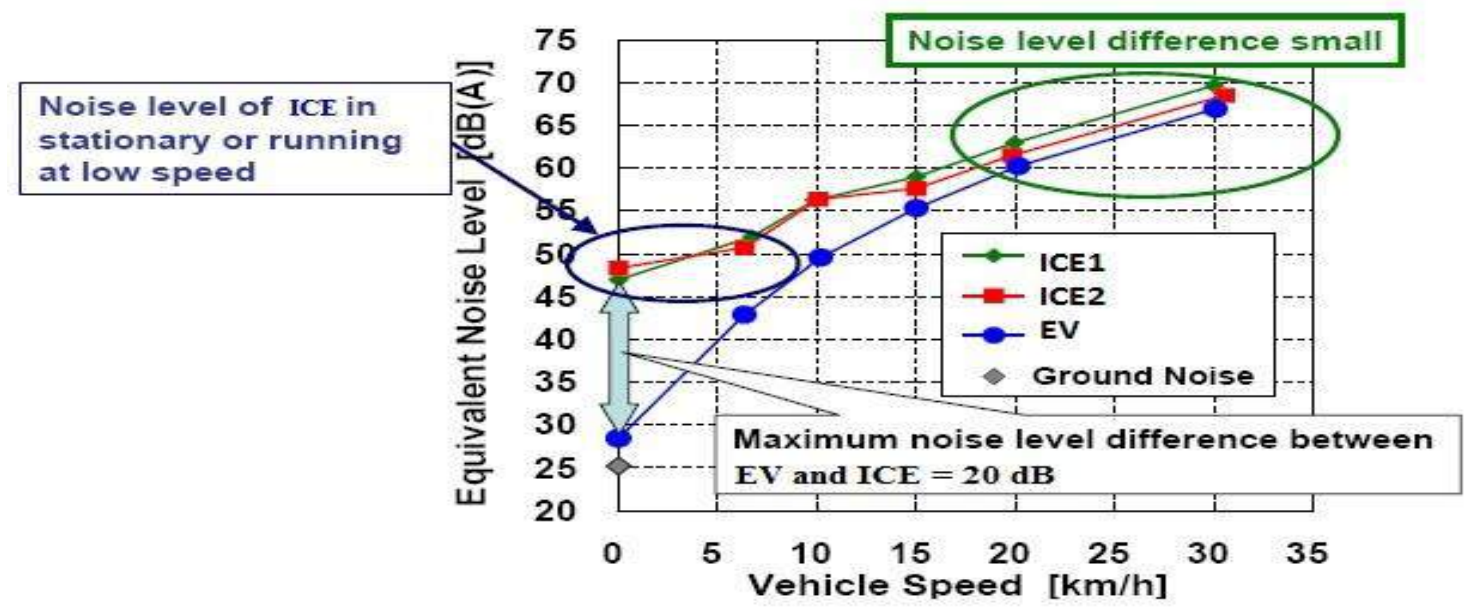

Figure 1. Noise level comparison between EV and ICE vehicles at various speeds

(Sandberg et al., 2011).

The background sound pressure level will also affect the noise level coming from the electric vehicle. Figure 2 shows that the distance perceived by pedestrians was not much different from a vehicle approaching at a speed of $20 \mathrm{~km} / \mathrm{h}$ for all types at various background noise levels. The same occurred when the vehicle approached at a speed of $15 \mathrm{~km} / \mathrm{h}$, where there was no significant difference, but at low ambient noise pedestrians started to find it hard to detect the EV. For vehicle speeds of 10 and $6.5 \mathrm{~km} / \mathrm{h}$, the perceptual distance between the EV and ICE vehicles kept decreasing, with a huge difference (Sandberg et al., 2011).

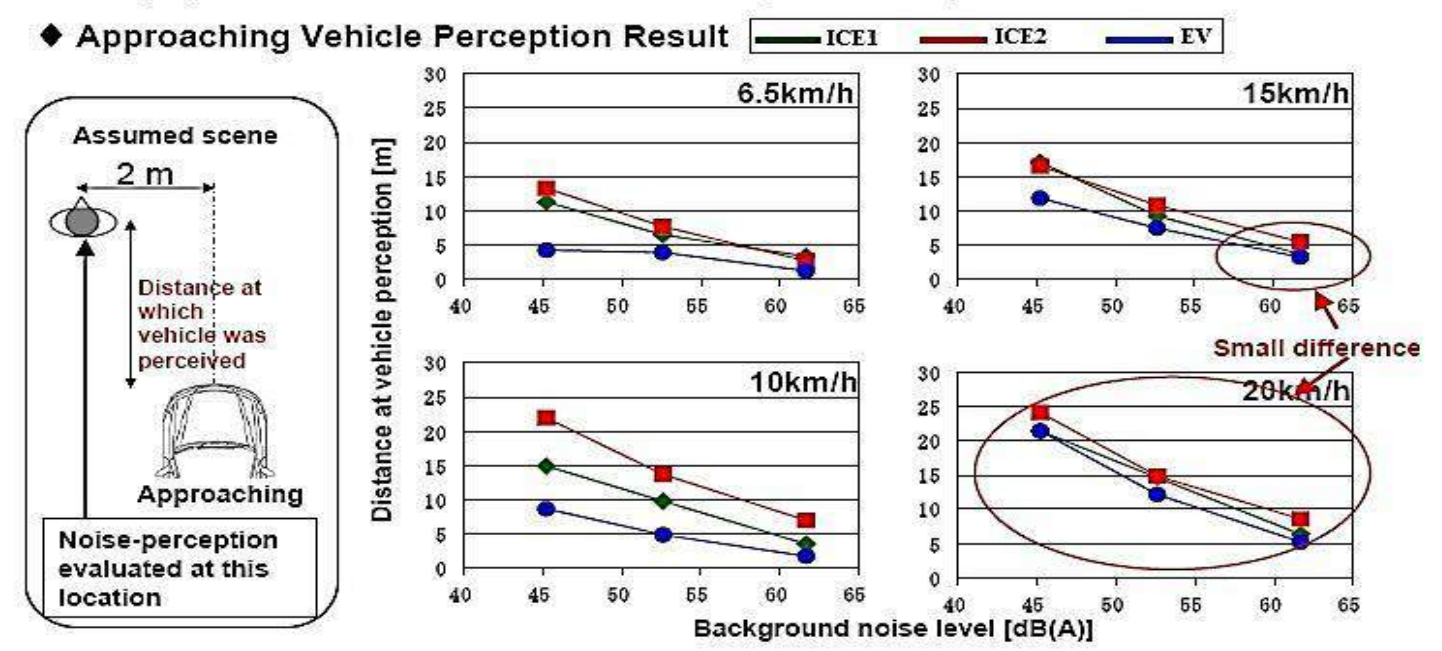

Figure 2. Results of a study on perception of sound from an approaching HEV car, compared to two ICE cars in Japan for three sites with different background noise 45-

$62 \mathrm{~dB}$ (Sandberg et al., 2011). 


\section{Hearing Threshold}

To develop a compatible backing up sound for the EV, the signal should be within the human hearing threshold in order for them to react to the approaching vehicle. The hearing threshold and the equal loudness contours of young persons with normal hearing are shown in Figure 3. Each equal loudness contour indicates combinations of level and frequencies that are perceived as equally loud for pure tones. Almost similar curves exist for narrow band noise (ECTunes, 2011). Normal people usually have sensitive hearing between $1.6 \mathrm{kHz}$ and $5 \mathrm{kHz}$ because of the resonance of the ear canal and the transfer function of the ossicles of the middle ear (Tabata et al., 2011).

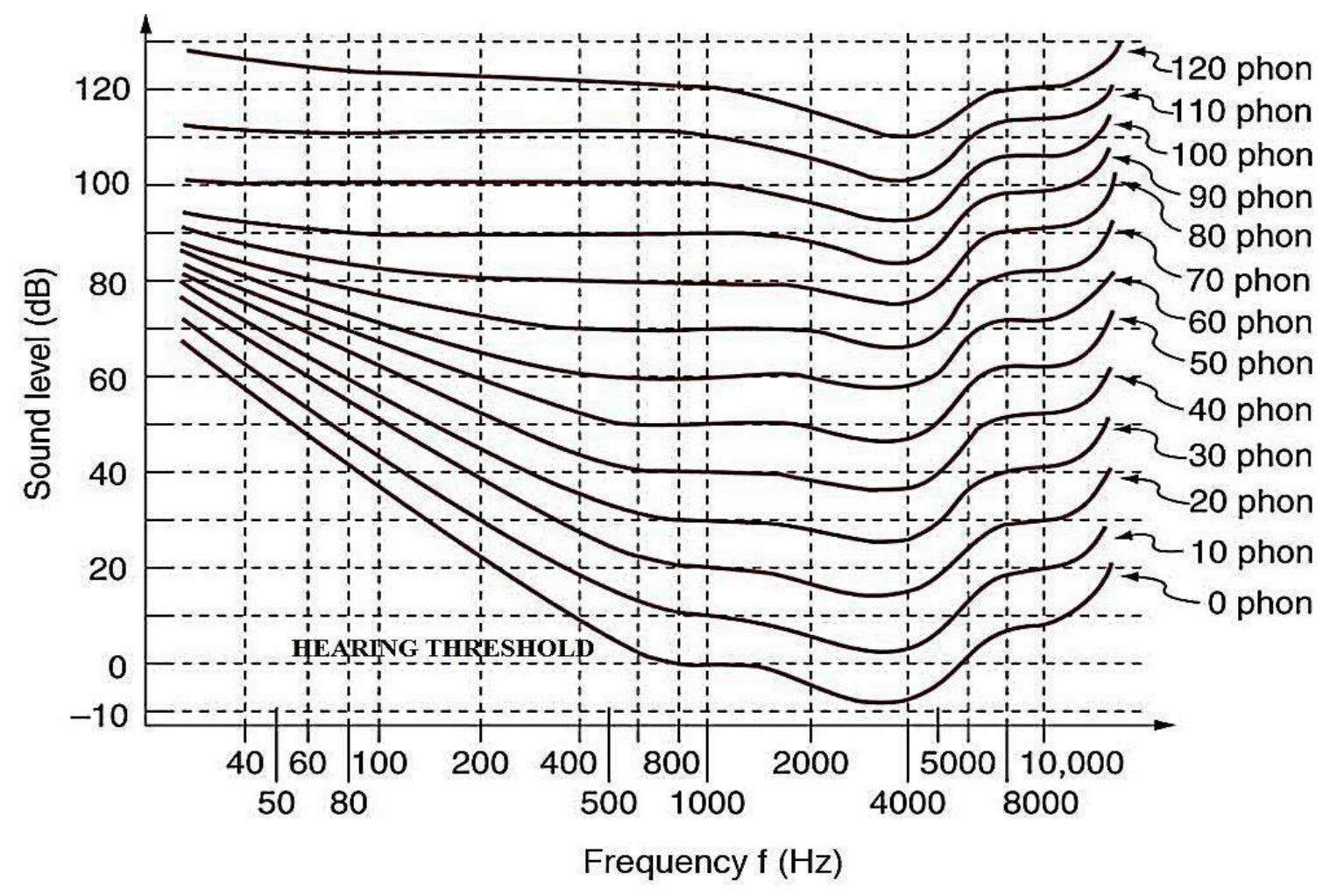

Figure 3. Normal hearing threshold and equal loudness curves from ISO 226 (OpenStax College, 2014).

Age also plays an important part in the human hearing threshold. As they grow older, people's hearing capability becomes less sensitive especially to high frequency signals and they also tend to develop presbycusis disease (age-related hearing loss). Figure 4 describes the age-related hearing loss for age-group ranges 30, 50 and 70 years old. Normally at this age range, hearing capabilities start to decrease from the normal threshold. From Figure 4, the compatible frequency signal for older people is below 2 kHz. For people in their 70's, their hearing capability drops drastically when the signal reaches $1 \mathrm{kHz}$ and above. The same is true of people at 50 years old, whose hearing sensitivity drops severely after the signal passes $2 \mathrm{kHz}$ (ECTunes, 2011). 


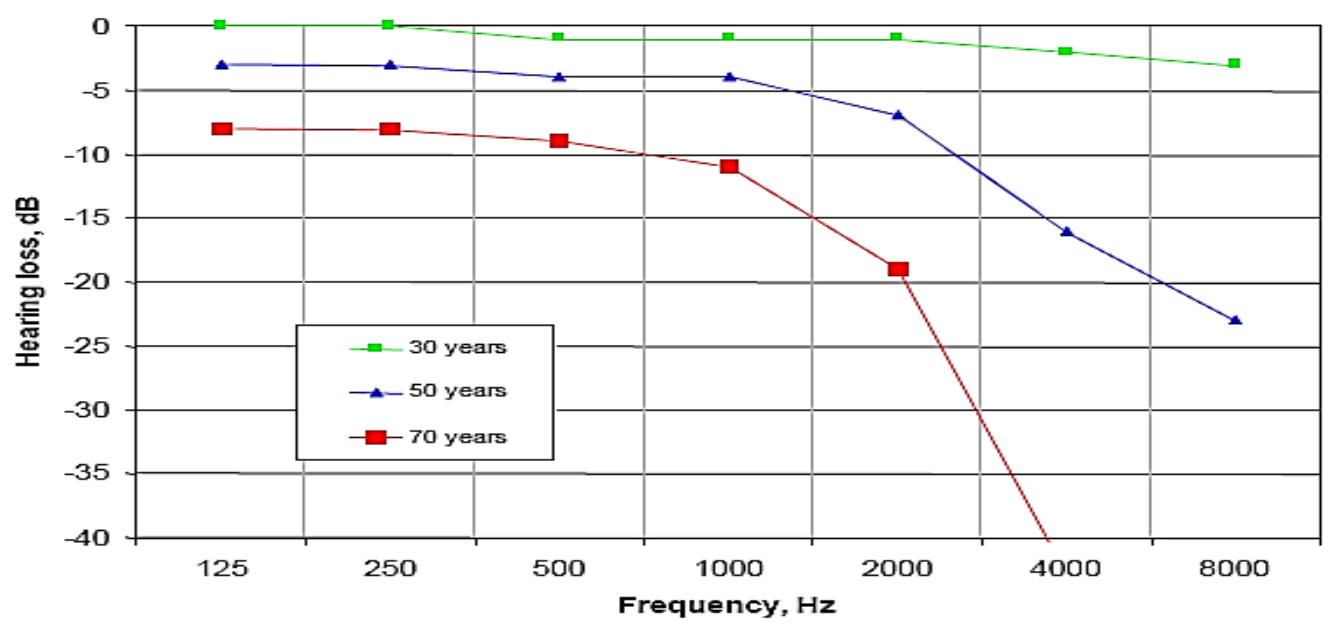

Figure 4. Average hearing threshold for different age groups according to ISO 7029 (ECTunes, 2011).

\section{Sound Annoyance}

When an individual or a group of people become irritated or uncomfortable (such that they believe it can affect their daily lives) by any state that is related to sound, that is called sound annoyance (Lindvall \& Radford, 1973). From a health perspective, some sound can be treated as toxic, as it affects the pleasure, wellbeing and health of a percentage of the exposed population. This toxicity suggests that these sounds can interfere with the most basic processes of life. This type of sound is called noise and it can cause stress, according to the World Health Organization (WHO) in 2011. To understand the annoyance of the sound, people must know how sound can have both positive and negative influences on them. In other words, people should know the pleasurability of sounds that can bring 'peace' to their lives and also that sounds can bring frustration and affect our daily routine. In terms of physiological reactions, people exposed to sound annoyance can find that it increases their heart rate and blood pressure, which may lead to hypertension (Lindvall \& Radford, 1973). These characteristics play an important role in back-up sound in the real environment. Reducing the annoyance of the sound can give benefits to the locality and especially residential neighborhoods, and can at the same time reduce noise pollution.

\section{Back-up Alarm Sound}

Back-up or reversing alarms are installed in vehicles to alert people in the vicinity for safety purposes. The alarm warns people to be aware and take action (if necessary) to move out of the danger area. The back-up signal must be heard by people on all sides of the danger spot. The danger area is the spot where, if a person crosses it, harm may be caused if the vehicle is moving, for example, at the rear of the vehicle (Teamsters, 2013). Nowadays, most car manufacturers use a back-up beeper or single frequency signal alert sound in their models. Unfortunately, our brain cannot deal with the repetitive and persistent sound of back-up beepers, but favors natural sounds that dissipate (Wolchover, 2012). Now an authority has urged researchers to develop a new set of motion alarms to alert pedestrians to the quietness of EVs when traveling at low speed (Holzman, 2011). The reverse alarm is meant to produce sound characteristics or 
separate sounds indicating that the vehicle is reversing that are added to the drive sound. The sound can be similar to the hauling of the reverse gear, 'pings' or a similar sound or short tone sequence (ECTunes, 2011). In the last few years, many newly designated acoustic signals have been introduced for vehicle back-up alarms and one of these was a broadband signal which is deemed to reduce the annoyance (Nélisse et al., 2011). Three types of back-up alarm, which are standard tonal signal, broadband signal and multitone signal, will be evaluated on their annoyance and suitability.

Tonal noise is a noise that is emitted to the environment which contains a high amount of energy in a single frequency, also known as 'pure tone'. Noise such as hums, hisses, screeches and drones are examples of tonal noise that contains a clear and continuous note (NÆRUM, 2007). A broadband frequency signal or white sound is a noise whose acoustic energy is distributed over a wide frequency range (Nélisse et al., 2011). The spectrum is largely smooth and continuous except at the extremes. The multi-tone signal was introduced by Laroche in 1995 and it was an improvement on the conventional tonal alarm. The multi-tone signal consists of several major tones between 1000 and $1300 \mathrm{~Hz}$, in contrast to a tonal alarm which is concentrated around $1250 \mathrm{~Hz}$, while for a broadband signal the energy is distributed over a large frequency and most of it is found in the range of 700 to $4000 \mathrm{~Hz}$, as illustrated in Figure 5 (Nélisse et al., 2011).

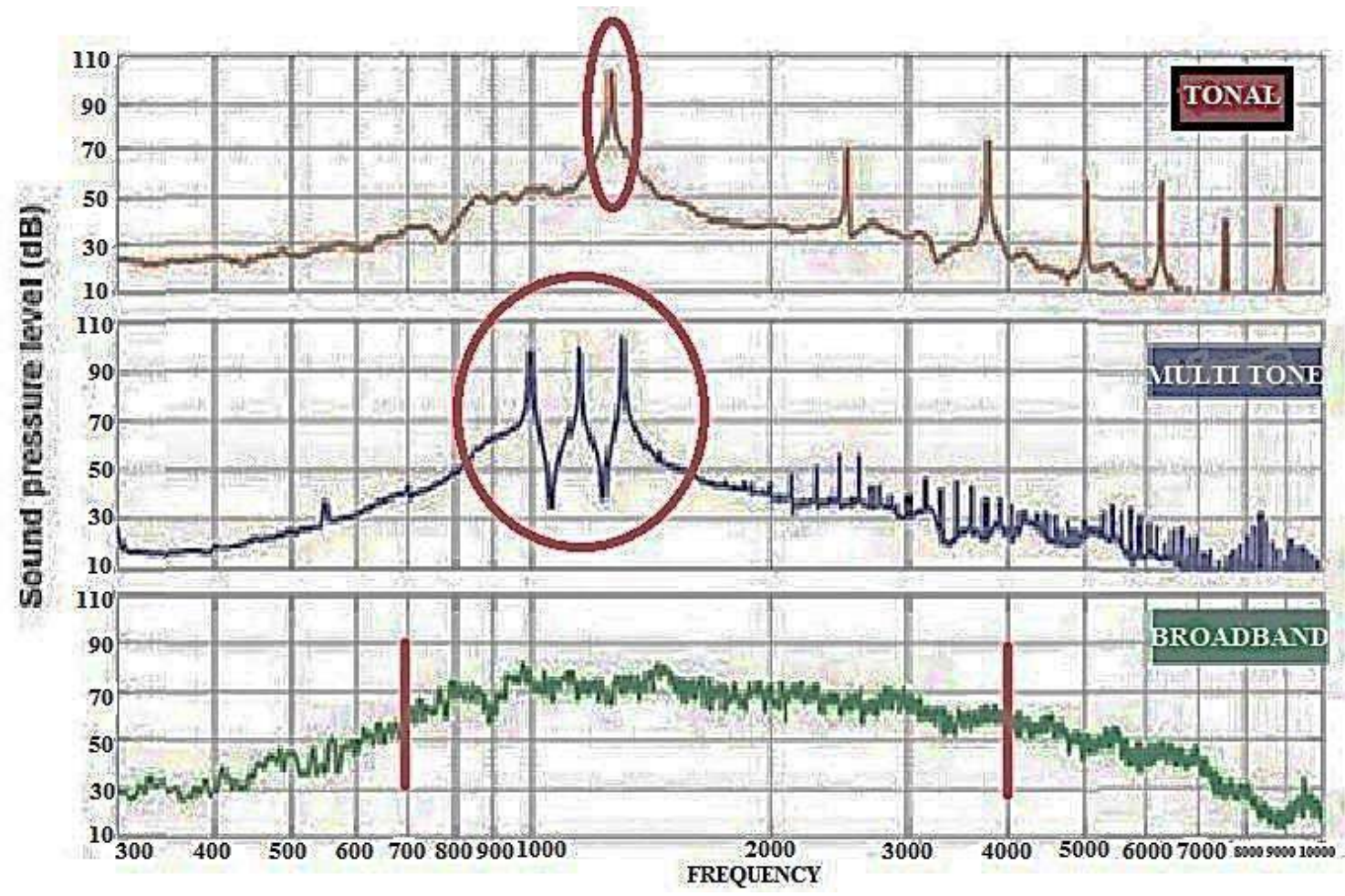

Figure 5. Frequency range for tonal, broadband and multi-tone signals (Nélisse et al., 2011).

\section{METHODOLOGY}

Three tested signals (broadband, tonal and multi-tone frequency signals) were used as a potential back-up warning alarm. These sounds were generated and analyzed using Audacity software and MATLAB software. One back-up sound signal from the Nissan 
Leaf (the first mass production Electric Vehicle) was used as benchmark for these three signals. The signals were evaluated by selecting respondents and obtaining their perceptions of the annoyance and suitability of the sound to be implemented on EVs in the real environment. The respondents evaluated the signal on annoyance by rating it on an evaluation form after they had listened to the sound through a Sony Lightweight Funky Metallic Headphone MDR-570LP. Five verbal categories of annoyance scale: Extremely - Very - Moderately - Slightly - Not at all, were used to rate the signals, this scale being in accordance with ISO 15666. The same approach was used for suitability evaluation, with five categories of verbal suitability scales: Excellent - Good - Fair - Poor - Bad, used as an indicator. Before starting the evaluation, the respondents were required to listen to instructions from the tester: "Your task is to assess the annoyance and suitability of the sounds. Imagine that you hear these sounds at home as part of the traffic noise. The sounds are neither more nor less prominent than the motor sound of the 'normal' cars. The sounds you will be listening to are constant since it was a back-up alarm". Fifty (50) respondents were selected to evaluate these signals from various types of residential area $(\mathbf{1 0}$ - university student \& staff, 10 neighborhood, 10 - rural/village area, 10 - town area, 10 - apartment/flat complex).

Three generated and one existing signal were evaluated for this research. The first was a broadband frequency signal. This signal was generated at the sampling rate of $44100 \mathrm{~Hz}$ for 0.6 seconds. Figure 6 plots the graph of the sample broadband signal (single tone) in the time and frequency domain (amplitude and decibel range). The signal was repeated continuously to act as an alarm sound for an EV back-up maneuver. Figure 6 (b) shows that the frequency energy of the sound is concentrated in the range of $0-5000 \mathrm{~Hz}$.
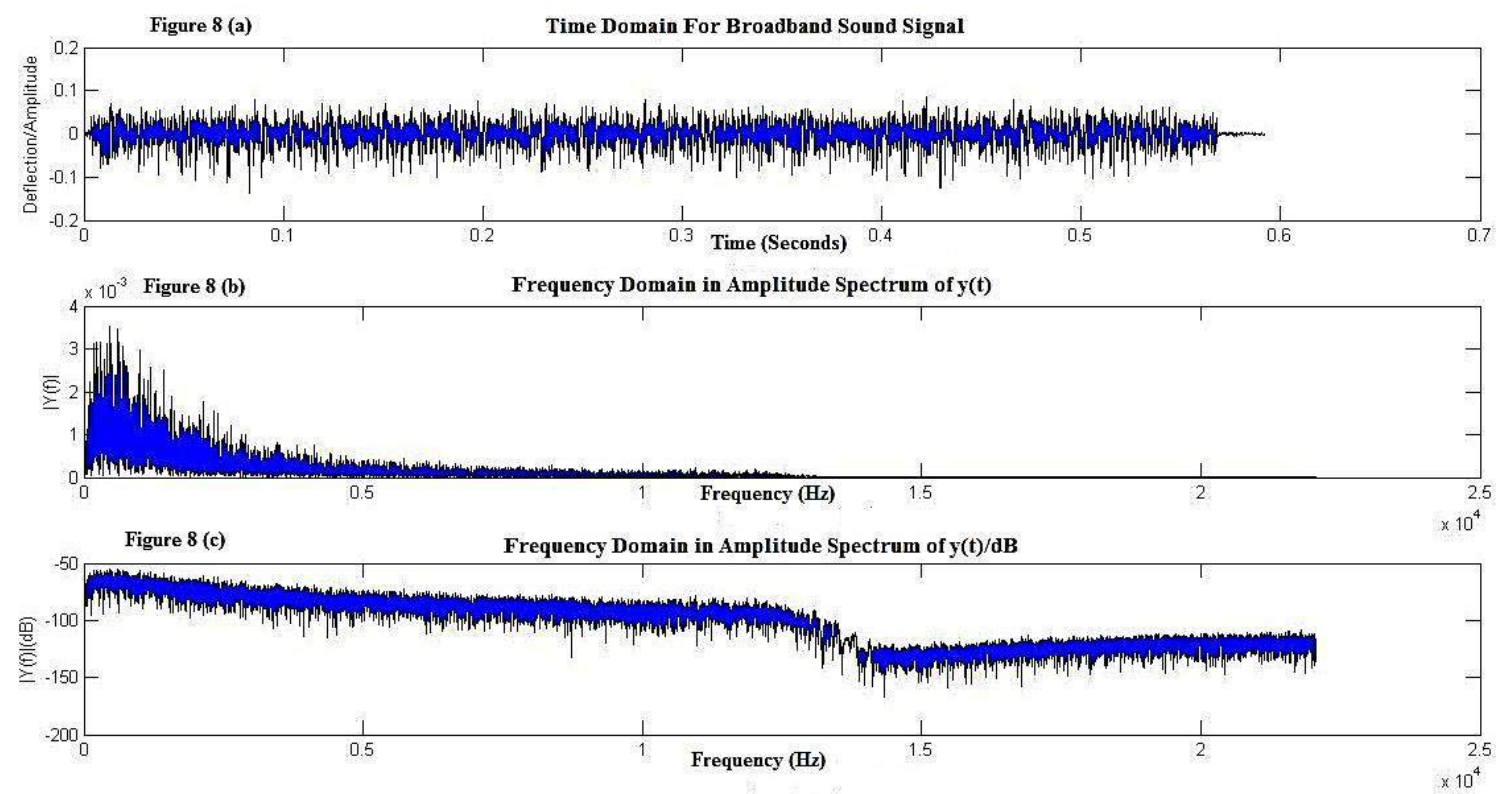

Figure 6. Time and frequency domain for broadband tested signal

The tonal signal that was used for the annoyance and suitability evaluation for this research was also generated at the sampling rate of $44100 \mathrm{~Hz}$ for 1 second. The sound was played repeatedly when the EV was reversing. Figure 7 (a) shows the signal in the time domain, 7 (b) shows the frequency domain-amplitude, and 7 (c) shows the 
frequency domain (decibels). The frequency energy signal for the sample sound was concentrated at $758 \mathrm{~Hz}$, as shown in Figure 7 (b).
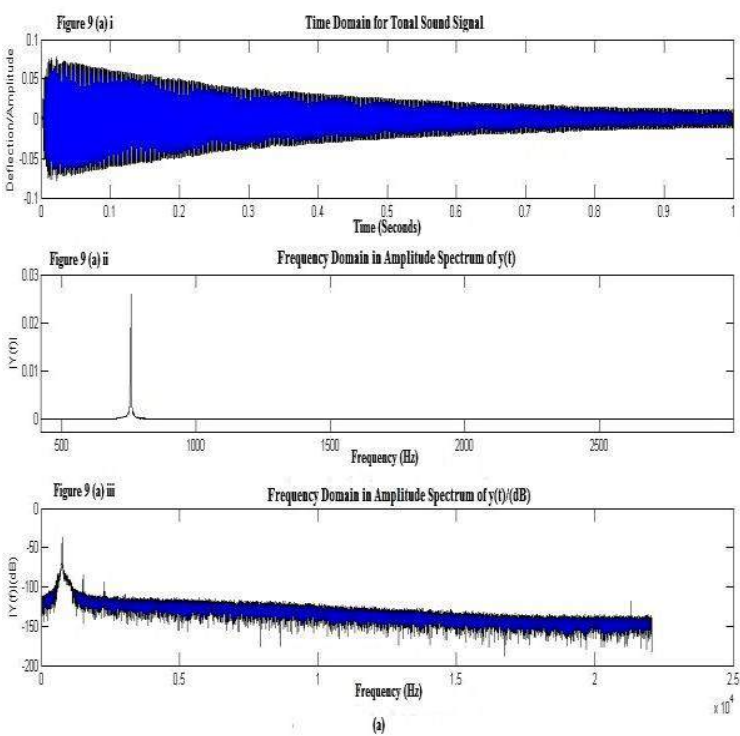
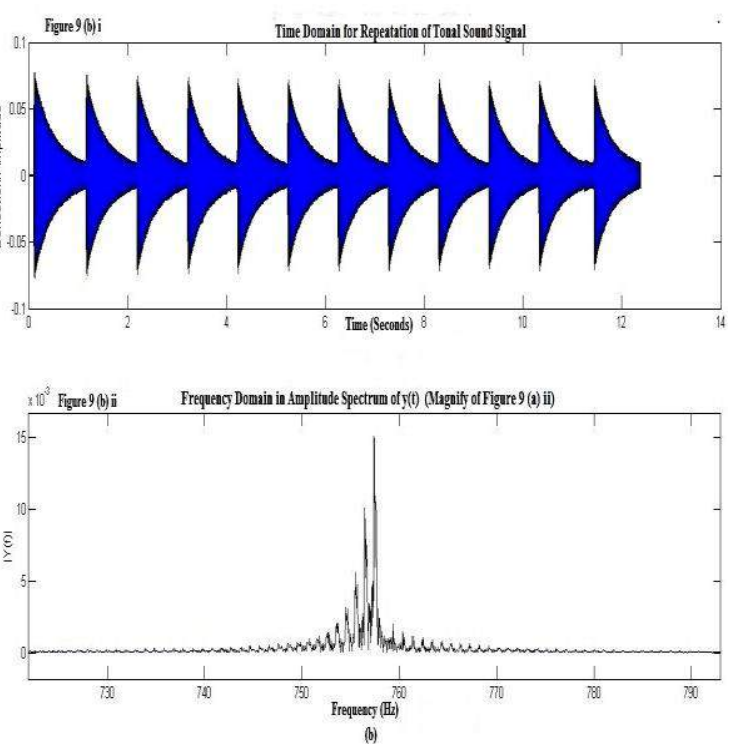

Figure 7. (a) Time and frequency domain for tonal tested signal; (b) Time and frequency domain (close-up) for repeated tonal signal

The multi-tone signal consisted of several major tones in a high frequency signal. For this research the tone's energy frequency was concentrated between $3000 \mathrm{~Hz}$ and $4000 \mathrm{~Hz}$ and was repeatedly played 3 times consecutively, as shown in Figure 8 (a) and Figure 8 (b).
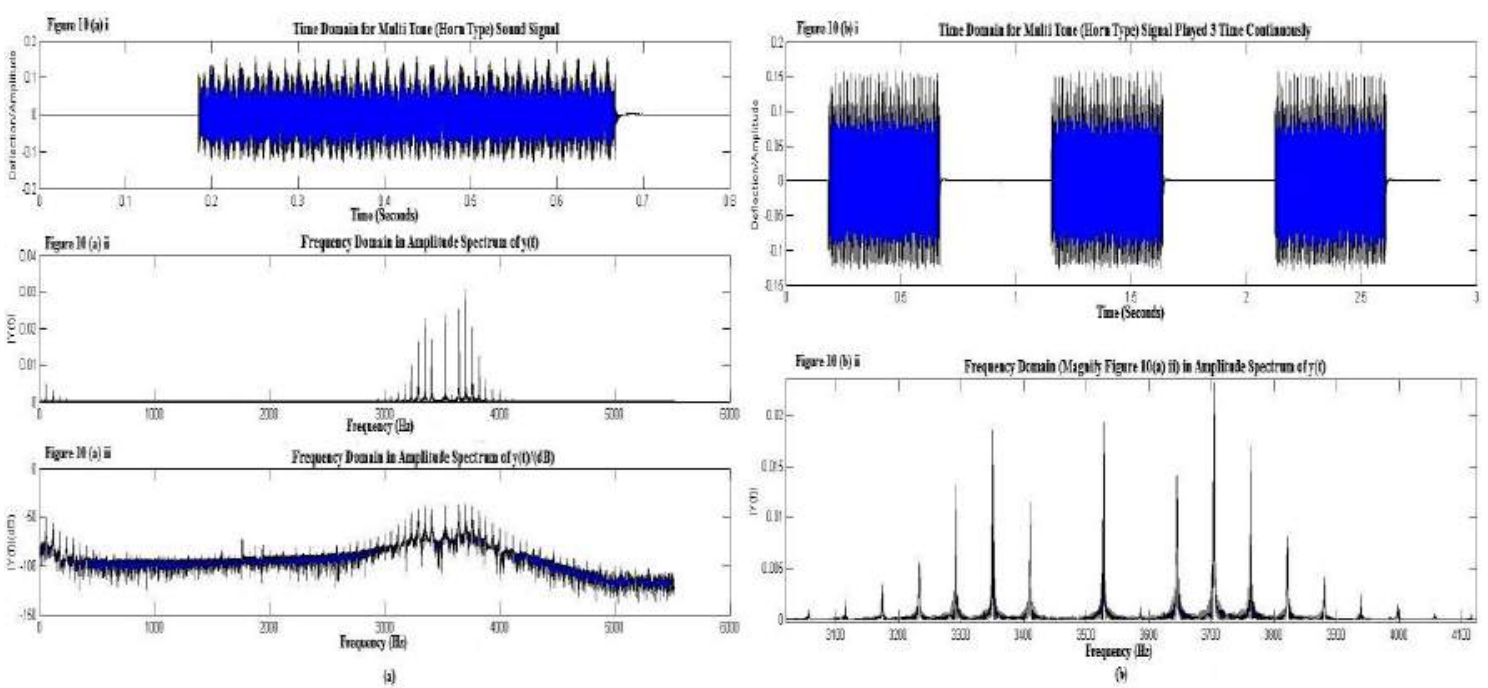

Figure 8. (a) Time and frequency domain for multi-tone (horn type) tested signal; (b) time and frequency domain (close-up) for 3 consecutive notes

\section{RESULTS AND DISCUSSION}

Based on the questionnaire results, Figure 9 (a) shows that for the annoyance evaluation the sound from the Nissan Leaf back-up alarm had the highest vote, with 9 respondents 
choosing the 'Extremely' category, followed by the multi-tone signal - 5 votes, broadband signal - 4 votes, and the tonal signal with only 2 votes. In the 'Very' annoyance category, the multi-tone signal received almost half of the vote from the respondents with 22 votes, followed by the Nissan Leaf back-up sound - 19 votes, broadband signal - 8 votes, and tonal signal - 7 votes. For the 'Moderately' annoyance section, 17 respondents voted for the broadband signal, followed by the tonal signal with 16 votes. The multi-tone and Nissan Leaf signals shared third place with 10 votes each. For the last category, which was 'Not At All' annoyed, 15 respondents chose the tonal signal and 12 chose the broadband signal. The multi-tone and Nissan Leaf signals received the least votes, with only 2 respondents declaring that the signal was not annoying at all. For the suitability evaluation, Figure 9 (b) shows the 'Excellent' categories received the votes of a total of 35 respondents, and the broadband signal had the highest vote with 12 , followed by the tonal signal - 11 votes, Nissan Leaf back-up signal - 7 votes and lastly the multi-tone signal with 5 votes. In the 'Good' section, the tonal and Nissan Leaf sounds led with 18 respondents voting for them. A total of 56 votes in the 'Fair' category, which turned out to be the highest vote of all the categories. For the last category, which was 'Bad', 14 respondents cast their votes in this section and the broadband signal got 5 votes, followed by the Nissan Leaf, multi- tone signal and tonal signal.

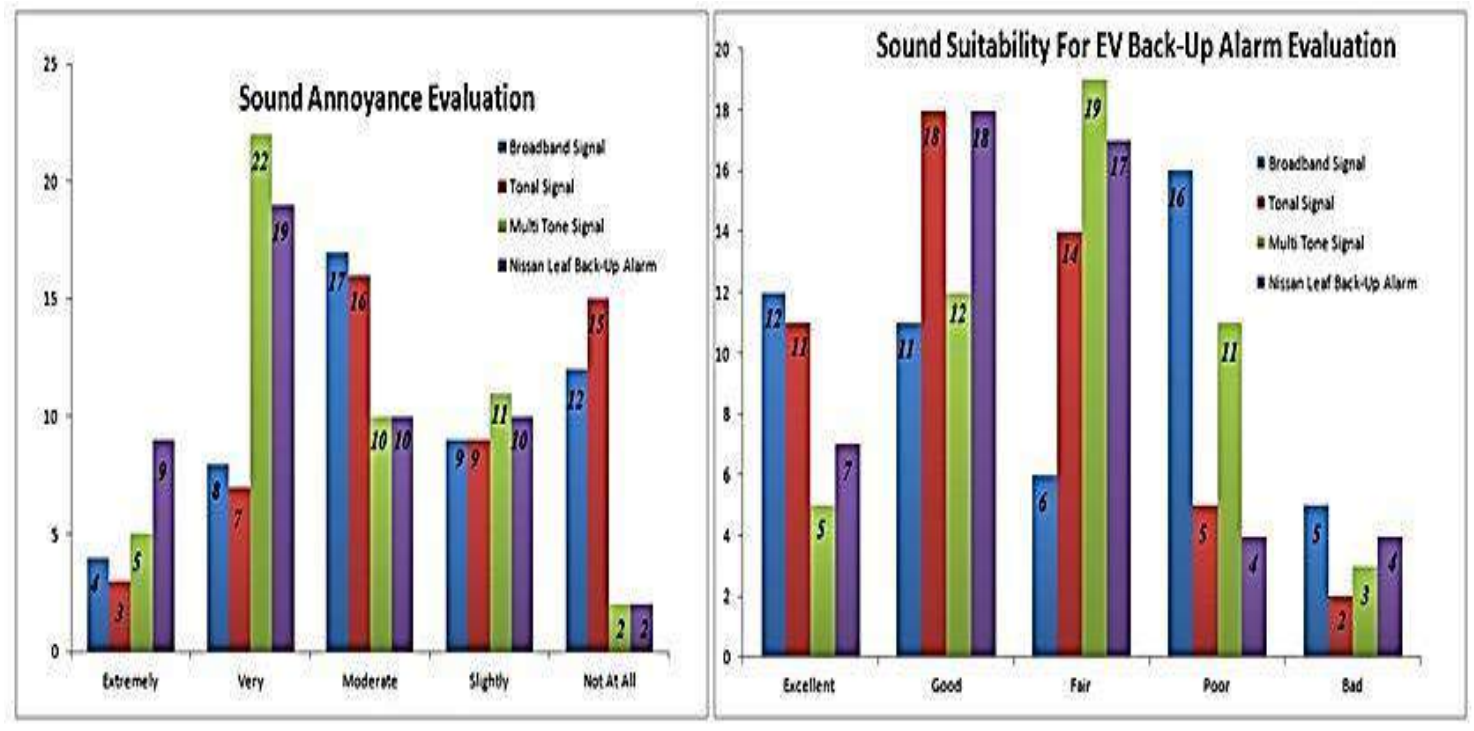

Figure 9. (a) Sound annoyance evaluation; (b) Sound suitability for EV back-up alarm evaluation (numbers indicate the total vote among the respondents)

An evaluation form was distributed to respondents in five different locations (rural/village area, town, neighborhood, university and apartment/flat complex) to see the correlation between background noise and sample sound. For the annoyance evaluation, two categories were selected for discussion (Extremely and Very Annoyed section), as shown in Figure 10. Only four respondents in the rural/village area voted in the Extremely section. These votes were for the Nissan Leaf back-up sound (2), while the tonal and multi-tone signals had one vote each. In the 'Very Annoyed' section, the multi-tone signal had the highest vote from these respondents, with 8 votes, while 1 vote each went to the tonal and Nissan Leaf sounds. Respondents in the town cast 1 vote each for the tonal, multi-tone and Nissan Leaf sounds in the 'Extremely Annoyed' 
section, but in the 'Very Annoyed' category the broadband signal got the highest vote, with 5 selecting this. The Nissan Leaf back-up sound also had the most votes in the neighborhood and university areas for the 'Very Annoying' section, with 7 and 6 votes.

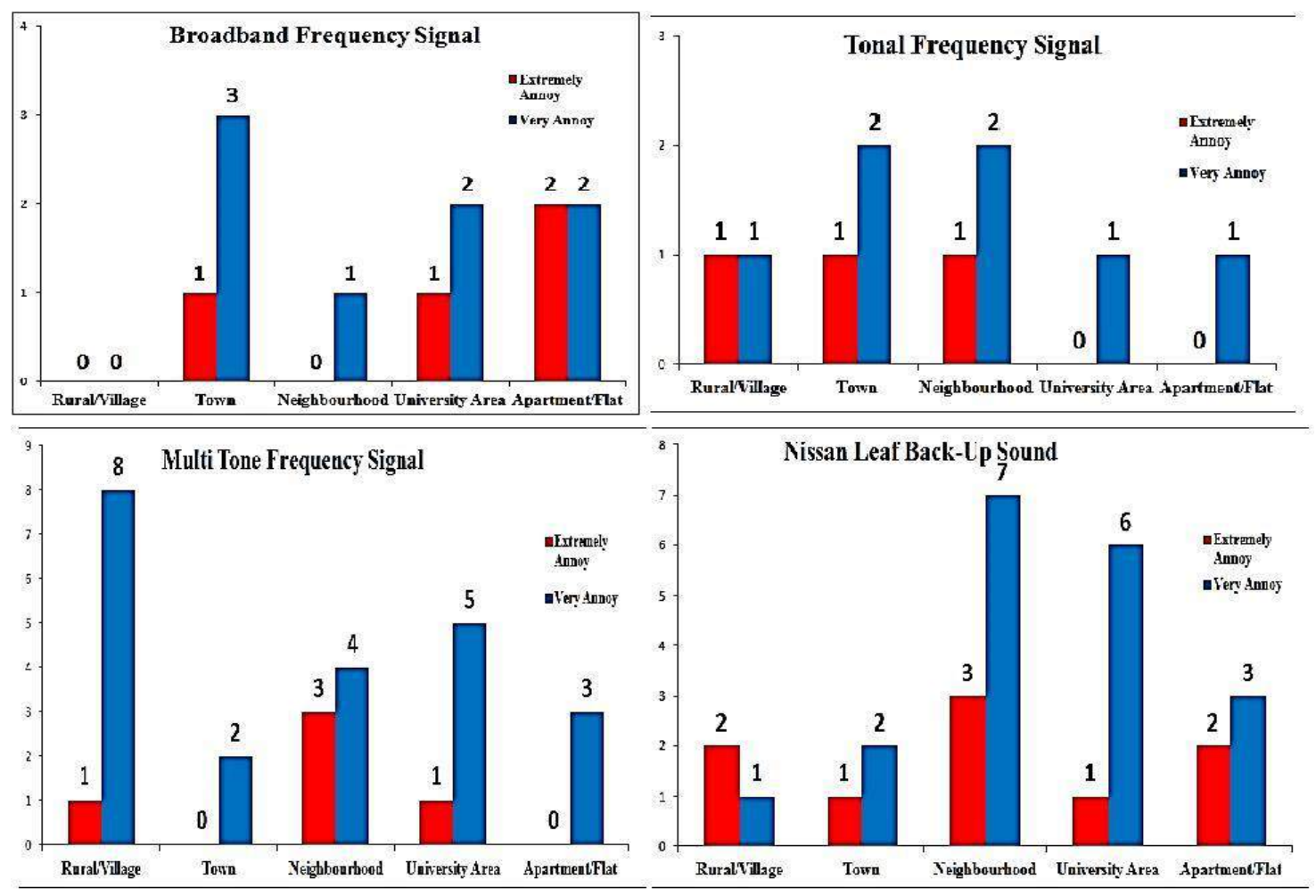

Figure 10. Sound annoyance evaluation according to place of living for 'Extremely Annoy and 'Very Annoy' categories (numbers indicate the total vote among respondents)

For Figure 11, 5 respondents in the neighborhood chose the broadband signal as 'Excellent', while people in rural and town areas rated the Nissan Leaf and tonal sounds as a 'Good' back-up sound for EV, with the highest votes. Most of the results from respondents regarding annoyance and suitability levels were influenced by the place of living. As we can see, respondents who live in the town area prefer a sound that can be heard clearly, such as the multi-tone signal and Nissan Leaf sound. This is because the background/ambient noise in urban areas was masking the sound coming from the vehicle, making it hard to hear and also possibly affecting their hearing capabilities. Respondents who live in rural areas choose instead a more comfortable sound to be heard as the EV back-up alarm, which is the broadband or tonal signal. The ambient level in this type of area is lower and for that reason most of the respondents do not favor high frequency sounds (multi-tone and Nissan Leaf) because these may annoy them. In the 'Extremely' and 'Very' annoyed categories, the multi-tone and Nissan Leaf signals obtained the majority vote compared to the broadband and tonal signals. This indicates that high frequency signals without filtration can create 'annoying' characteristics in the signal. As for the tonal signal used in this research, in the beginning it caused some annoyance, but after being filtered the frequency of the signal was reduced to the hearing threshold level. 


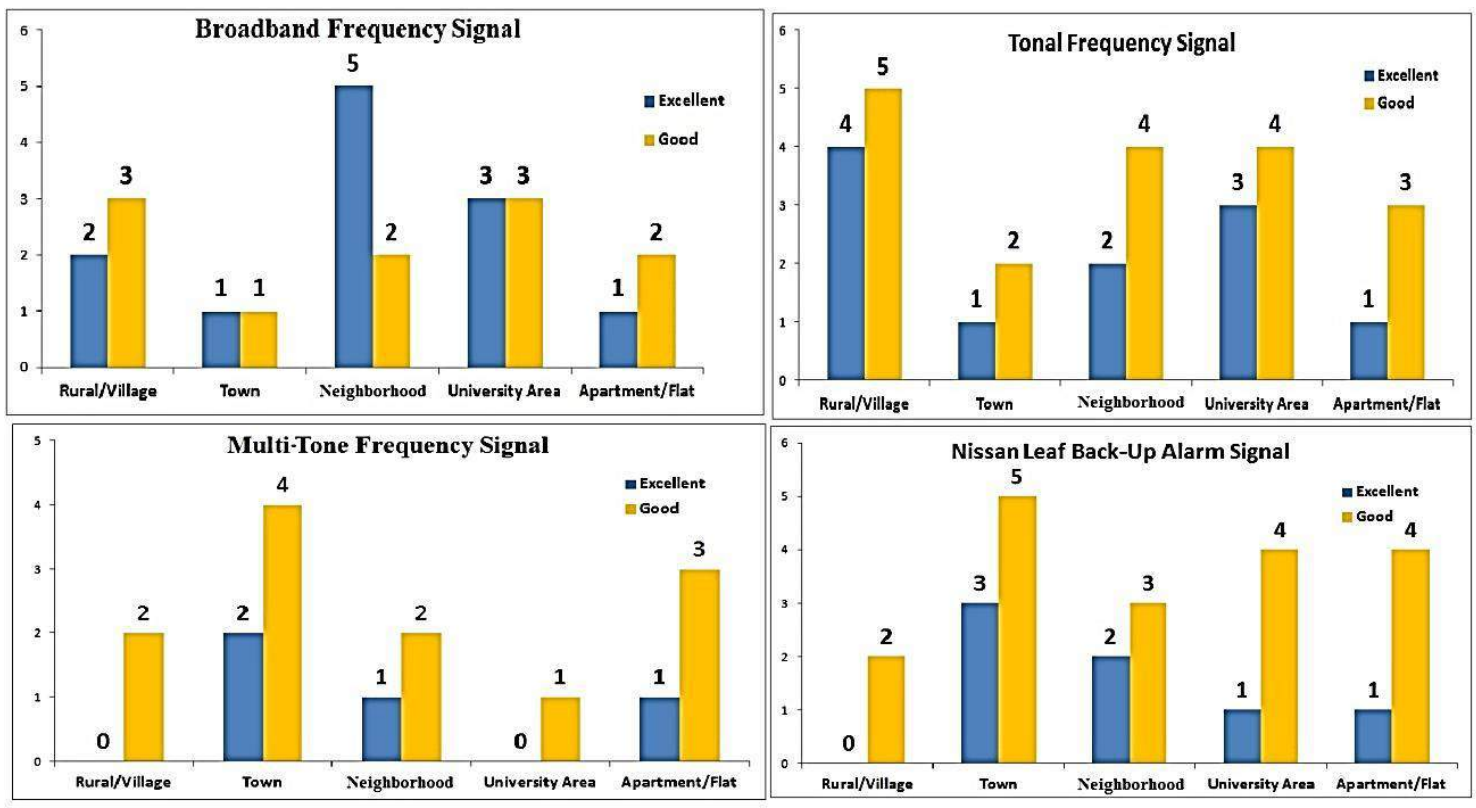

Figure 11. Sound suitability evaluation according to place of living for 'Excellent' and

'Good' choice categories (numbers indicate the total vote among respondents)

\section{CONCLUSION}

In conclusion, we can see that broadband and tonal signals are most acceptable as a back-up sound for EVs to alert pedestrians. In the annoyance evaluation, most of the respondents put these two signals not in the 'Extremely' or 'Very' annoying categories, but more in the 'Moderate' section, in contrast with the multi-tone and Nissan Leaf sounds. The suitability evaluation shows that respondents are also most likely to choose these two signals as preferable for EV back-up alarms, even though some respondents were in favor of the multi-tone and Nissan Leaf sounds because of their clearer and sharper characteristics helping to alert pedestrians. However, although in this research the broadband and tonal signals were preferred, the detectability and localization characteristics of these signals to pedestrians remain uncertain. A detectability and localization evaluation test should therefore be conducted on these signals to obtain a reliable result for implementation as EV back-up alarms.

\section{ACKNOWLEDGMENTS}

The authors wish to thank the Universiti Teknologi Malaysia (UTM) for providing the funding and facilities to conduct this research.

\section{REFERENCES}

ECTunes (2011). White paper on external warning sounds for electric cars Recommendations and guidelines. Denmark: ECTunes.

Holzman, D. C. (2011). Vehicle motion alarms: Necessity, noise pollution, or both? Environmental Health Perspective, 119(1), A30-A33.

JASIC (2009). A study on approach warning systems for hybrid vehicle in motor mode. Informal document No. GRB-49-10 (49th GRB, 16-18 February 2009), GRB, WP29, ECE, Geneva, Switzerland. 
Lindvall, T. \& Radford, E. P. (1973). Measurement of annoyance due to exposure to environmental factors. Environmental Research, 6, 1-36.

Nélisse, H., Laroche, C., Boutin, J., Giguère, C., \& Vaillancourt, V. (2011). Propagation of sound behind vehicle equipped with different backup alarm. Journal of University of Ottawa, 39(3).

NÆRUM (2007). Investigation of tonal noise. Press Release, http://www.bksv.com/NewsEvents/News/InvestigationOfTonalNoise.aspx, Denmark, (Accessed on 27 January 2012).

OpenStax College-Physics of Hearing, http://cnx.org/content/m42297/ latest/?collection=col11406/latest (Accessed on 9 January 2014).

Otto, N. C., Simpson, R., \& Wiederhold, J. (1999). Electric vehicle sound quality. Noise and Vibration Conference \& Exposition, Traverse City, Michigan, May 17201999.

Sandberg, U., Goubert, L., \& Mioduszewski, P. (2010) Are vehicles driven in electric mode so quiet that they need acoustic warning signals? $20^{\text {th }}$ International Congress on Acoustics, ICA, PACS: 43.50Lj, 43.66.Qp

Tabata, T., Konet, H., \& Kanuma, T. (2011). Development of Nissan approaching vehicle sound for pedestrians. Copyright (C) 2011 SAE International and Copyright (C) Society of Automotive Engineers of Japan, Inc, 2011-39-7231

Teamsters Local Union (2009). No. 555. Retrieved from http://www. teamsters155.org/web2009/index.php.

Wolchover, N. (2012). Everyday things that make you dumb: Why mundane experiences can throw your mental muscles for a loop. Reader's Digest, September 2012, p. 37. (Retrieved on 28 October 2012).

Zeitler, A., BMW Group (2012). Psychoacoustic requirements for warning sound of quiet cars. SAE International, doi:10.4271/2012-01-1522. 